\title{
Development of large scale inland flood scenarios for disaster response planning based on spatial/temporal conditional probability analysis
}

\author{
Elizabeth Wood ${ }^{1}$, Rob Lamb ${ }^{1 . a}$, Sarah Warren ${ }^{1}$, Neil Hunter ${ }^{1}$, Jonathan Tawn ${ }^{2}$, Richard Allan ${ }^{3}$ and Stefan Laeger ${ }^{4}$ \\ 1 JBA Consulting, South Barn, Broughton Hall, Skipton, North Yorkshire, BD23 3AE, United Kingdom \\ ${ }^{2}$ Department of Mathematics and Statistics, Lancaster University, LA1 4YF, United Kingdom \\ ${ }^{3}$ Department of Meteorology, University of Reading, Berkshire, RG6 6BB, United Kingdom \\ ${ }^{4}$ Environment Agency, Manley House, Kestrel Way, Exeter, EX2 7LQ, United Kingdom
}

\begin{abstract}
Extreme event scenarios are useful for civil emergency services to help in developing contingency plans for responding effectively to major flooding incidents. In the UK, the official national risk register includes a scenario for inland flooding (from rivers and other sources), which is described in terms of a probability of occurrence over a five year period of between 1 in 200 and 1 in 20 . This scenario was previously based on recent extreme floods, in conjunction with maps produced to aid in development planning on floodplains. At the time it was constructed, it was not feasible to assess scientifically the combined probability of a nationally-significant flood event of this type, therefore the scenario probability assessment was ambiguous.

Recent developments in multivariate extreme value statistics now allow the probability of large scale flood events to be assessed with reference to hydrological summary statistics or impact metrics. Building on theory and pilot studies by Heffernan and Tawn [1], Lamb et al. [2] and Keef et al. [3], we describe the development of a set of national-scale scenarios based on a high-dimensional (ca. 1,100 locations) conditional probability analysis of extreme river flows and rainfall. The methodology provides a theoretically justified basis for extrapolation into the joint tail of the distribution of these variables, which is then used to simulate extreme events with associated probabilities. The probabilistic events are compared with current understanding of meteorological scenarios associated with significant, large-scale flooding in the UK, and with historical flooding, in order to identify plausible events that can inform national risk scenarios. Additionally, we combined scenarios of inland and coastal extremes that have been considered by linking the analysis discussed in this paper with methods presented in a companion paper by Wyncoll et al.
\end{abstract}

\section{Introduction}

It is difficult to assess the probability of widespread or multiple-source flooding events such as those that occurred in the UK in Summer 2007 or Winter 20132014. Recently-developed joint probability methods [1] offer more flexibility to represent such events $[2,3]$. This work addresses the need for realistic, probabilistic scenarios accounting for spatially extensive inland flood events across England and Wales to support the 2016 update to the Government's National Risk Assessment [4]. Currently, inland flooding events in the NRA are expressed in terms of events with an encounter probability of between 1 in 200 and 1 in 20 years. However, the assessment of the probability of flood events is ambiguous without full joint probability analysis. This work improves the science underpinning the probability assessment of scenarios for the NRA and the quality of evidence through better quantification of scenario probability using existing statistical methods.

This paper outlines the drivers and methodology used for the development of scenarios for the 2016 National

\footnotetext{
a Corresponding author: rob.lamb@jbatrust.org
}

Risk Assessment. It also presents a comparison of one selected scenario with Storm Desmond which caused widespread flooding across Cumbria in the north-west of England on 5 and 6 December 2015.

\section{Drivers for development of probabilistic scenarios for widespread flooding}

There are two main drivers for this work:

1. To deliver scenarios for the 2016 National Risk Assessment, to meet the needs of Government and civil contingencies planning at a national or broad scale.

2. To deliver information on flood hazard joint probabilities for use by flood and coastal risk management specialists. 


\section{Methodology}

The Heffernan and Tawn [1] methodology is a practical, flexible, data based joint probability model which has been tried and tested in flooding applications (Lamb et al., 2010 [2], Keef et al., 2013 [3]) and was assessed to be suitable to meet the requirements of the NRA [4].

Scenarios for both inland fluvial flooding and surface water are required for the NRA. River flow data were initially obtained for over 1,500 gauging stations and rainfall data were obtained for over 1,400 tipping bucket rain gauges (TBR) across England and Wales. Extensive quality checks were carried out to ensure the data were suitable for inclusion in the analysis including checks of record length, completeness and hydrometric quality. A large number of gauges were removed after quality checks had been completed - the final numbers of gauges used were 682 flow gauges the fluvial scenarios and 190 TBRs for the surface water scenarios.

The statistical modelling methodology was implemented using an open source code package texmex [5] - in the $\mathrm{R}$ statistical programming language. A large number of statistically plausible events were simulated from the joint probability model, both for extreme river flows (relating to fluvial flooding) and extreme rainfall (relating to surface water flooding) using the methods described in [3] and [6]. From the simulation, events within the desired joint probability band (between 1 in 200 and 1 in 20 over a five year time horizon, Figure 1) and with the desired spatial characteristics (see below) were shortlisted for consideration as potential scenarios for the NRA.

\subsection{Scenario selection for the National Risk Assessment}

From the events simulated, events within the desired joint probability band (between 1 in 200 and 1 in 20 for the 5-year encounter probability, Figure 1) and with the desired spatial characteristics were shortlisted for consideration as potential scenarios for the NRA. The return periods for each event were plotted to provide a spatial overview of events and allow for identification of affected areas.

Scenario probabilities were assessed by summarising each proposed event in terms of the mean, $\mu$, of the simulated river flows over all affected gauges, ranking all simulated scenarios with respect to $\mu$ and deriving a probability estimate based on the ranks, using the Weibull formula $i /(n+1)$, where $i$ is the rank of the $i^{\text {th }}$ event, and $n$ is the number of events. The most extreme simulated event has an annual exceedance probability of approximately 1 in 10,000 , the rank two event has an annual exceedance probability of approximately 1 in 5,000 , and so on.

To meet the criteria of the NRA, the events needed to satisfy the criteria: $1000 \geq(10,000+1) / \mathrm{k} \geq 100$, i.e. events needed to have an annual exceedance probability of between 1 in 1,000 and 1 in 100 . The ranks corresponding to these probabilities are ranks 10 to 100 , with rank 10 being the most extreme event of this selection and subsequent ranks decreasing in extremeness.

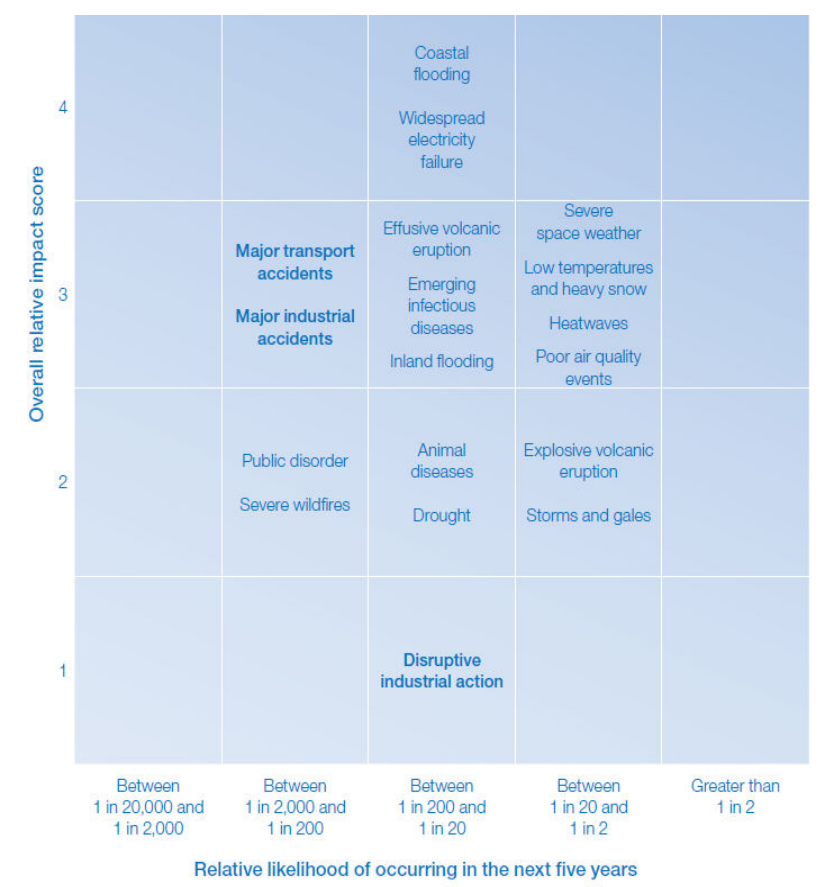

Figure 1. Encounter probability matrix from the National Risk registers (Cabinet Office, 2015 [7])

In addition to the ranking by the mean event return period, fluvial events were also ranked by consideration of exposure to flood risk, where property counts in Flood Warning Areas (FWA) were used as a proxy for exposure to risk. For each simulated event, the number of properties in a FWA was multiplied by the event probability at the nearest gauge. The scores for each FWA were summed to create an event exposure-based score. The event with the largest exposure score was the rank 1 , most extreme event.

The shortlist for fluvial events consisted of 15 events within the required range for the NRA using both the hydrological and exposure based ranking methods. For surface water flooding there is no simple exposure proxy equivalent to the FWA property counts, therefore shortlisted events were identified using the mean return period over all simulated gauge locations.

For each of the shortlisted fluvial and surface water events, the hydro-meteorological plausibility was considered. Any events which were not considered to be plausible were removed from the shortlist and were not considered as potential scenarios for the NRA.

\section{Application to fluvial flooding}

\subsection{Scenario development}

A total of four fluvial scenarios were required for consideration for the NRA. All scenarios needed be within the desired joint probability band of the National Risk Register. There were also end-user requirements for 
one scenario to affect the Thames catchment specifically, and another to affect the Trent catchment.

The meteorological plausibility of each of the shortlisted scenarios was considered qualitatively, and any which were not considered to be plausible were removed from the shortlist.

For each of the selected scenarios, a scenario narrative was devised. The narrative contained an overview of the event, a possible hydro-meteorological context for its occurrence and also some historical context, comparing the scenario to past flooding events.

Fluvial scenario 1 (Figure 4a) presents a severe event across London and much of the South East. Extreme returns periods are present across much of the Thames catchment with a return period of 800 years at Kingston and 300 years at Dorchester. There are also some high return periods on the East Coast.

Fluvial scenario 2 (Figure $4 \mathrm{~b}$ ) is a widespread event affecting most of England and Wales. Swathes of high return periods are present across the country. The Trent catchment is particularly affected with a return period of 450 years at Colwick in Nottingham. Several other gauges in the catchment have return periods in excess of 100 years.

Fluvial scenario 3 (Figure 4c) affects Southern England, Wales and North West England. The highest return periods are in Wales and the south of England. The Thames is severely affected with a return period in excess of 2,000 years at Kingston. Around Wrexham, a large number of gauges have return periods in excess of 100 years with some in excess of 50 of years. Scenarios such as this pose a challenge for emergency resource and planning and may be useful for emergency services to develop contingency plans for responding effectively to major flooding events.

Fluvial scenario 4 (Figure 4d) has four distinct centres of impact - North Wales, Yorkshire, South West England and Surrey. At least one gauge in each of these four areas has a return period in excess of 1,000 years. This scenario was selected so as to illustrate an event in which emergency response resources could be stretched by multiple simultaneous flood emergencies spread widely across the country.

\section{Application to surface water flooding}

\subsection{Scenario development}

Two surface water scenarios were required, including one with impacts in London. As for the fluvial scenarios, the meteorological plausibility of each shortlisted scenario was considered and any which were not plausible were removed. An accompanying narrative for each scenario was also constructed in the same way.

Scenario 1 (Figure 2) has considerable impact in London with a number of gauges having return periods in excess of 300 years. There are also a number of gauges just outside London with extreme return periods as well as a cluster of high return periods in north Birmingham.

Scenario 2 (Figure 3 ) is concentrated on the north of England with extreme return periods of 100 to 200 years across Greater Manchester and Merseyside. There are also some more isolated rural areas of extreme return periods in Settle and the Forest of Bowland.

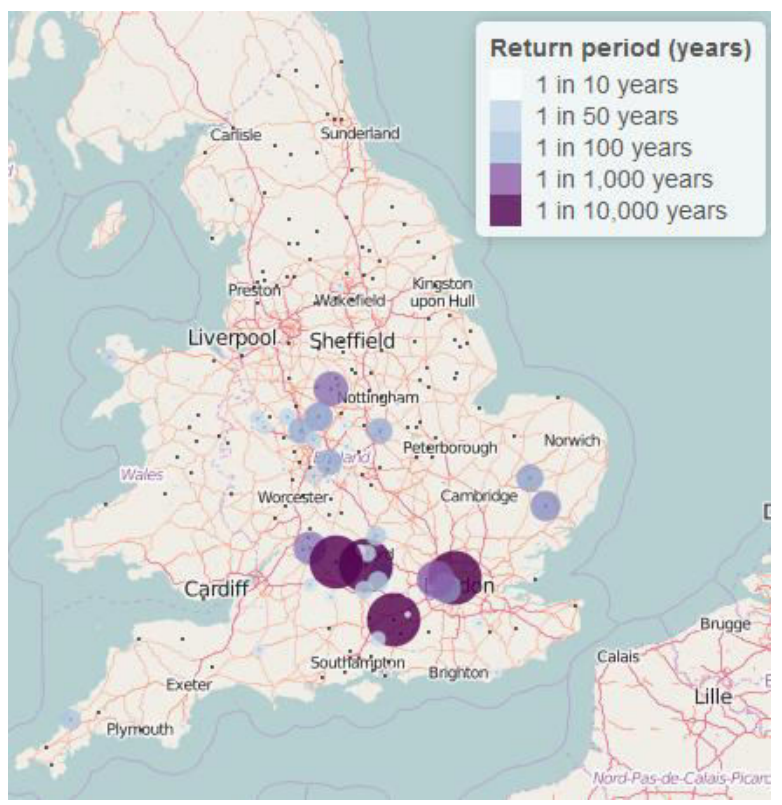

Figure 2. Surface water scenario 1 - high return periods in southern England, with London being particularly affected.

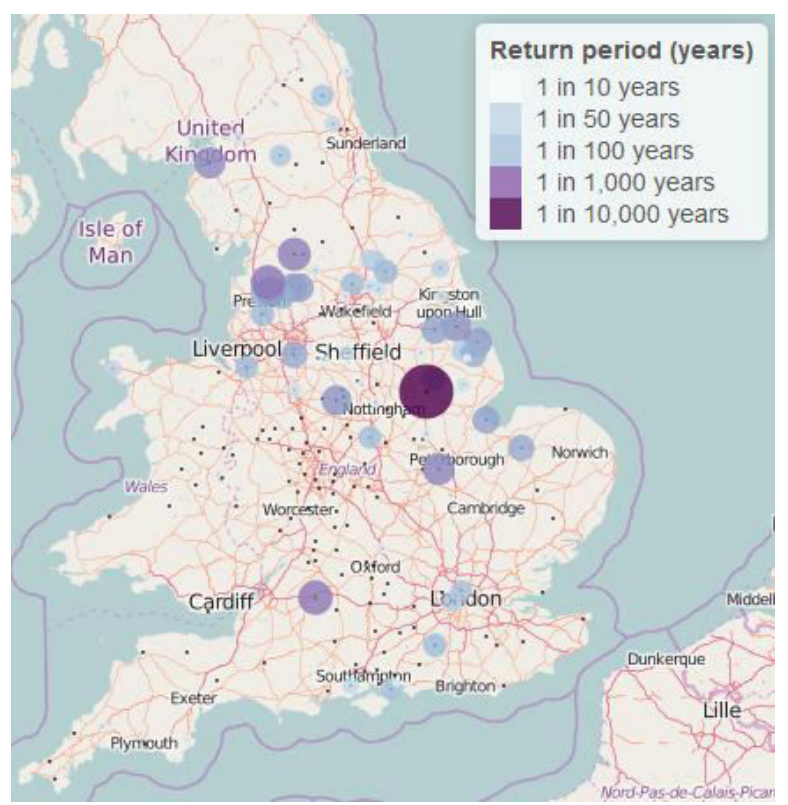

Figure 3. Surface water scenario 2 - high return periods across northern England 


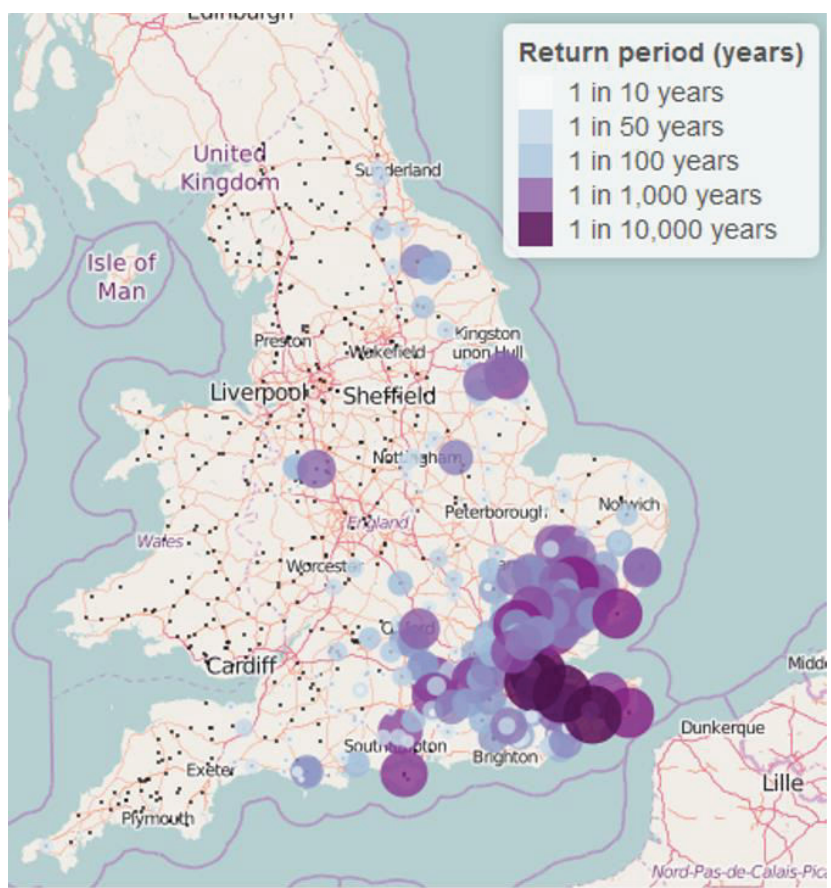

(a) Scenario 1

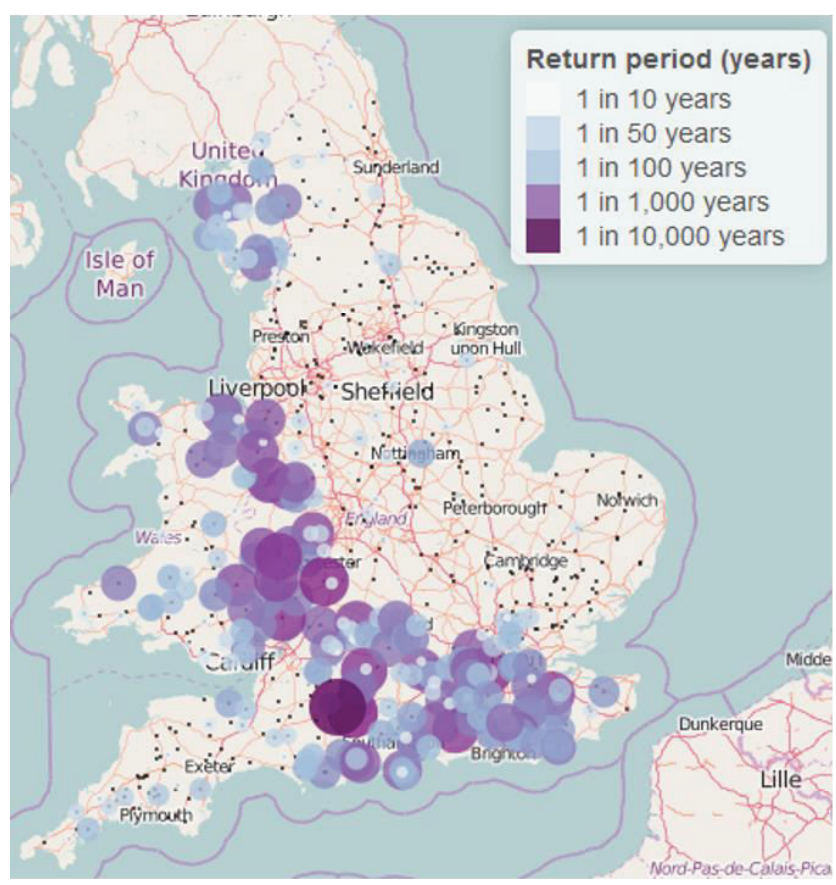

(c) Scenario 3

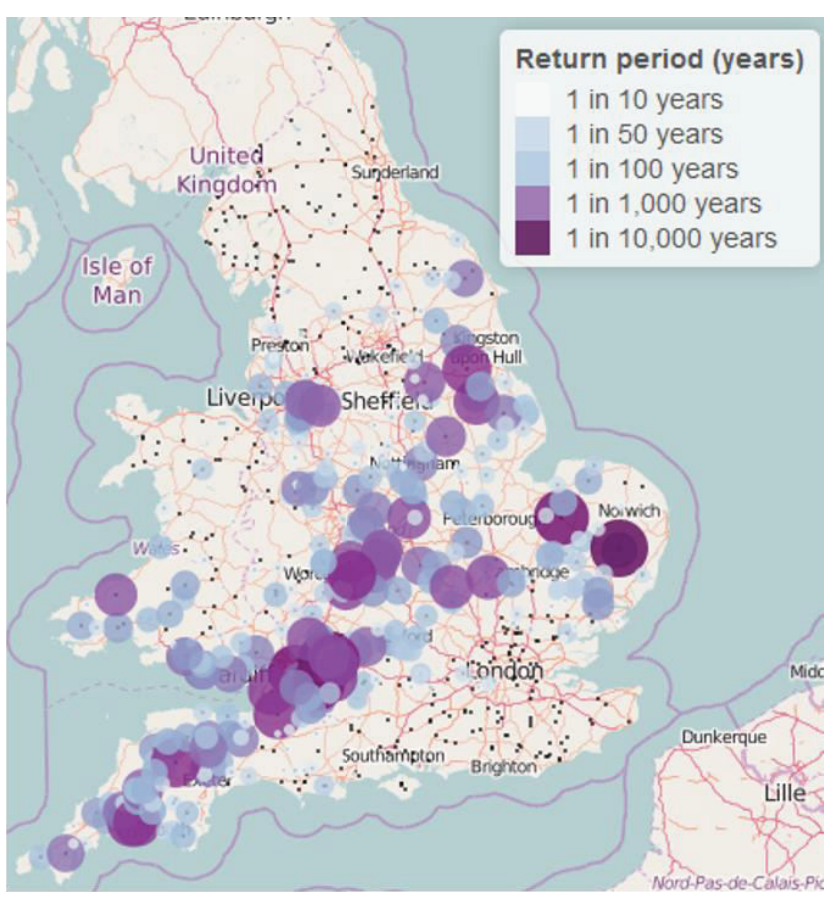

(b) Scenario 2

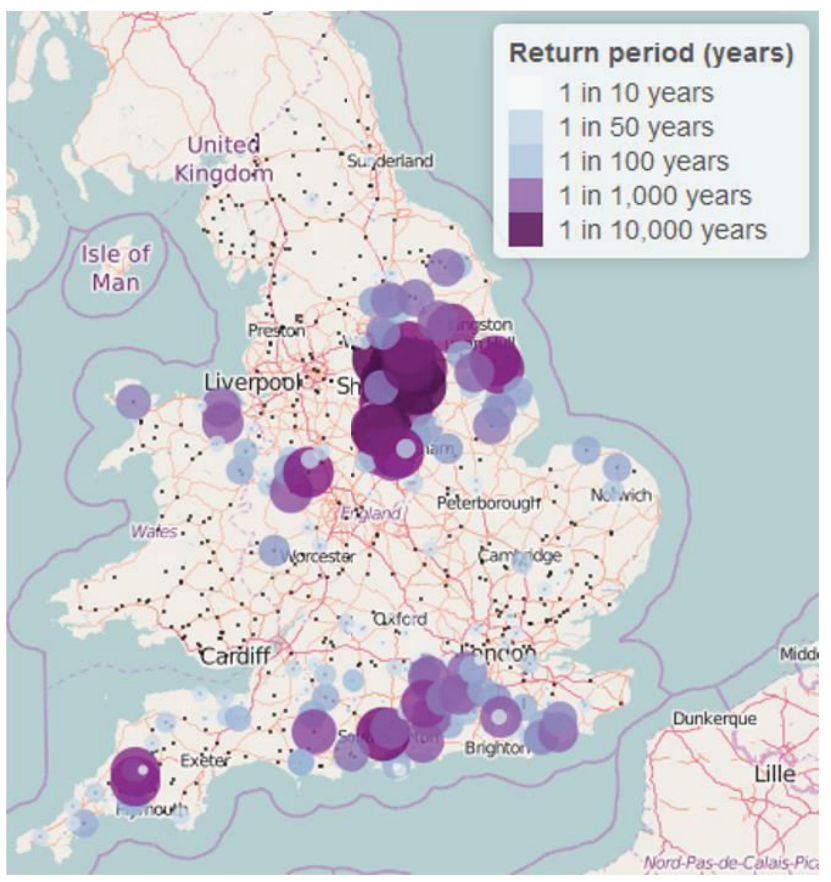

(d) Scenario 4

Figure 4. Fluvial scenario overviews 


\section{Hazard modelling}

In order to calculate the consequences of flooding associated with each scenario, hazard footprints were developed using 2D hydrodynamic modelling. Probabilities evaluated at each river flow/rain gauge were interpolated to the required spatial coverage and combined with standard UK flow and rainfall estimation methods to provide suitable boundary conditions to the hydraulic models. The models were then run on a High Throughput Cluster and the outputs combined to produce a single flood map for each scenario. These flood maps provide the basis for calculating economic damages and other impact metrics.

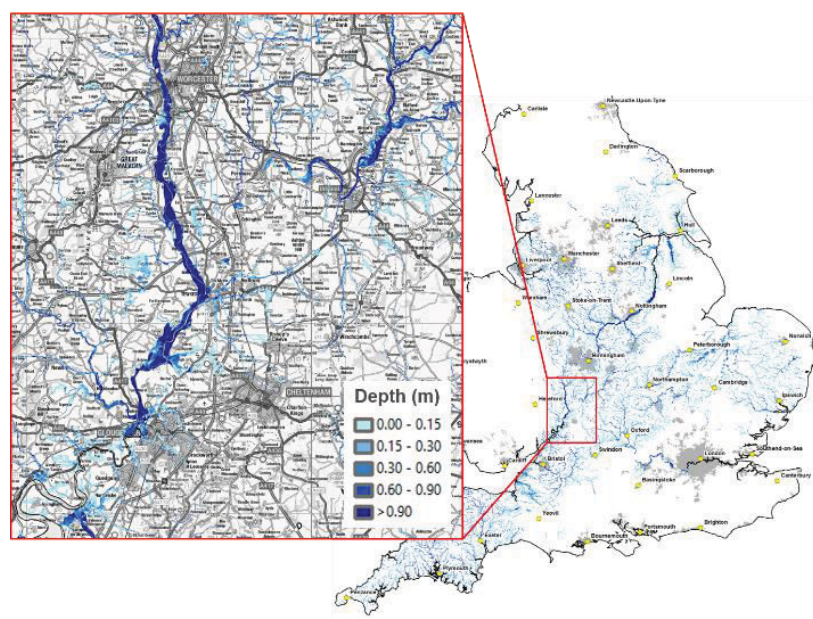

Figure 5. Widespread floodplain inundation associated with the example scenario shown in Figure $4 b$

\section{Storm Desmond comparison}

Storm Desmond impacted on the UK on 5 and 6 December, with severe gales and record breaking rainfall. At Honister Pass in Cumbria $341.4 \mathrm{~mm}$ of rain was recorded from 1800 on 4 December to 1800 on 5 December, and the 48 hour record was broken at Thirlmere in Cumbria with $405 \mathrm{~mm}$ of rainfall recorded [8].

Flooding occurred throughout Northern England during Storm Desmond, with Lancashire and Cumbria particularly affected. A number of bridges were washed away and Carlisle was affected by flooding from the River Eden [9].

To compare Storm Desmond to the proposed scenarios for the NRA, analysis of return periods and flow values for a select number of gauges was performed. Of the four fluvial scenarios proposed for the NRA, Scenario 3 (Figure 4c) has extreme return periods in North West England and was selected as the scenario for comparison.

River level data was obtained for 27 gauges in North West England over the course of Storm Desmond, from the Environment Agency's flood and river level data realtime data API (beta). River levels were then converted to peak flows using high flow rating curves from the NRFA Peak Flows database. The return period of each peak flow was calculated using the Generalised Extreme Value
(GEV) parameters derived in the joint probability model (Figure 6). For the scenario, flow values for each gauge were calculated using the scenario return period and associated GEV parameters.

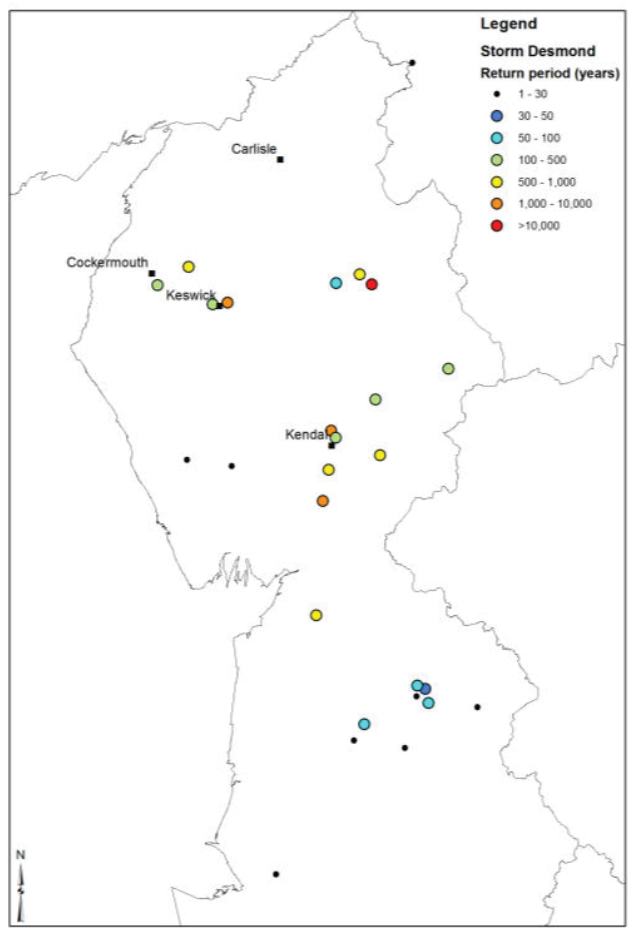

Figure 6. Return periods at selected gauges across Cumbria during Storm Desmond (5 - 6 December 2015), using the Environment Agency's flood and river level data from the real-time API (beta).

Figure 7 shows the comparison of return periods for Storm Desmond and the scenario, with a number of key locations highlighted. The comparison of flow values is shown in Figure 8. Any points above the 1:1 line indicate that Storm Desmond was more extreme at these locations and conversely, any points below the line indicate that the scenario was more extreme. Overall, the scenario simulations were comparable with the flows experienced during Storm Desmond, but those gauged flows were somewhat more extreme than the scenario within the Cumbria region. At the 27 gauges analysed, the maximum scenario return period is around 800 years, whereas for Storm Desmond, the maximum return period is around 1,500 years. It should be noted, of course, that the scenario also includes areas of more extreme high flood flows in other parts of the country that were not affected during December 2015. 


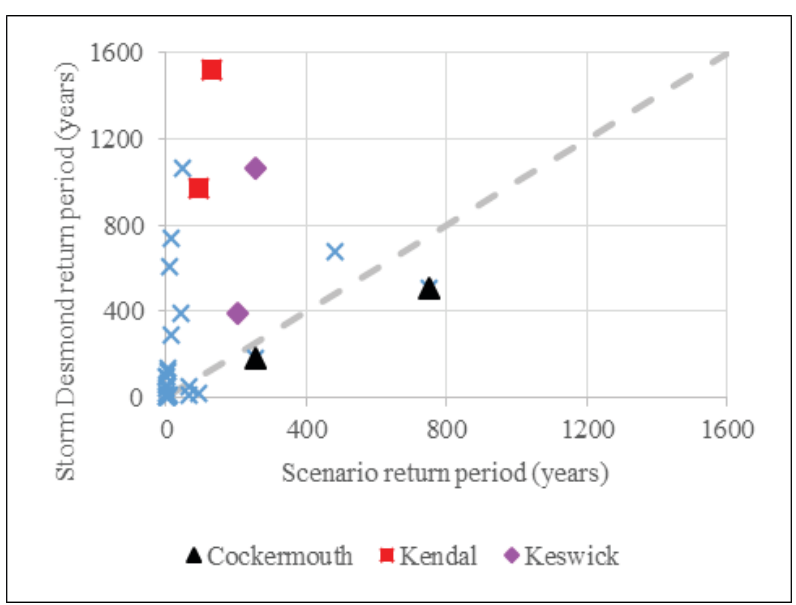

Figure 7. Comparison of fluvial scenario 3 return periods with return periods for Storm Desmond at selected gauges in North West England.

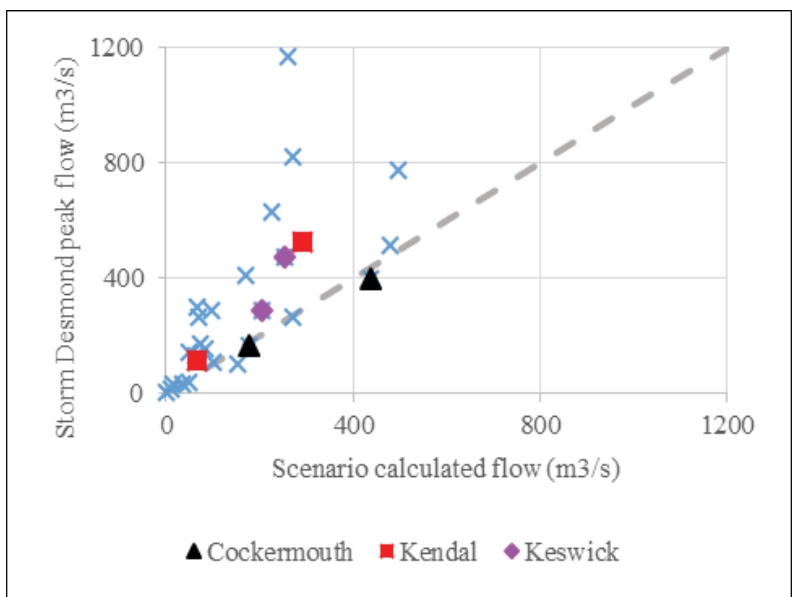

Figure 8. Comparison of flow values from Storm Desmond with fluvial scenario 3 flow values at selected gauges in North West England.

\section{Conclusions}

Historical flow and rainfall data were carefully collated and a sophisticated statistical joint probability model used to generate a large number of statistically plausible events for fluvial and surface water flooding. Having assessed the likelihood of the simulated events, a small number of events were selected as potential scenarios for the 2016 update to the National Risk Assessment.

The selected scenarios include a range of possible flooding events across England and Wales, including fluvial scenarios affecting the Thames and Trent catchments and a surface water scenario affecting London. Recent flooding helps to place such scenarios in context, as illustrated by comparison of one of the scenarios with the floods of December 2015 in Cumbria.

The scenario data has been mapped using detailed hydraulic modelling that can provide locally-detailed information to inform "what-if" planning of emergency responses. These outputs will support national assessment of flood emergency response, derived within a formal probabilistic framework.

\section{References}

1. Heffernan J. E. and Tawn J. A. (2004). A conditional approach for multivariate extreme values. Journal of the Royal Statistical Society, Series B (Statistical Methodology), 66(3), 497-546

2. Lamb R., Keef C., Tawn J., Laeger S., Meadowcroft I., Surendran S., Dunning P. \& Batstone C. (2010). A new method to assess the risk of local and widespread flooding on rivers and coasts. Journal of Flood Risk Management, 3 (4), 323 - 336

3. Keef C., Tawn J. A. and Lamb R. (2013). Estimating the probability of widespread flood events. Environmetrics, 24(1), 13-21

4. Cabinet Office (2012). National Risk Register for Civil Emergencies - 2012 update. https://www.gov.uk/government/publications/nationa 1-risk-register-for-civil-emergencies-2012-update (accessed 1 March 2016)

5. Keef C., Lamb R., Tawn J., Dunning P., Batstone C. and Lawless M. (2011). The risk of widespread flooding - Capturing spatial patterns in flood risk from rivers and coasts. SC060088/R1 Spatial Coherence of Flood Risk - Technical Methodology Report. Environment Agency. http://evidence.environmentagency.gov.uk/FCERM/Libraries/FCERM_Project Documents/SC060088_report_1.sflb.ashx (accessed 19 February 2016)

6. https://cran.rproject.org/web/packages/texmex/index.html

7. Cabinet Office (2015). National Risk Register of Civil Emergencies 2015 edition. https://www.gov.uk/government/uploads/system/upl oads/attachment_data/file/419549/20150331_2015NRR-WA_Final.pdf (accessed 19 February 2016)

8. Met Office (2016). Storm Desmond - Met Office. http://www.metoffice.gov.uk/uk-storm-centre/stormdesmond (accessed 12 February 2016)

9. Met Office (2016). Flooding in Cumbria December 2015.

http://www.metoffice.gov.uk/climate/uk/interesting/d ecember2015 (accessed 12 February 2016). 